\title{
Phylogenetic position of Miliusa vidalii (Miliuseae, Annonaceae) inferred from chloroplast DNA and morphology
}

\author{
Axel H. Arriola ${ }^{1}$, Ma. Catherine M. Noche ${ }^{1}$, Emmanuel A. Tangco $^{1}$, Abigail A. Vicente ${ }^{1}$, \\ Mariel B. Santos ${ }^{1}$ and Grecebio Jonathan D. Alejandro ${ }^{2}$
}

\begin{abstract}
A molecular phylogenetic study was conducted to determine the position of the Philippine endemic Miliusa vidalii in the tribe Miliuseae of family Annonaceae utilizing the combined cpDNA sequence data (trnL-F-matK-ndhF-psbA-trnH-ycf1). Bayesian inference and Maximum parsimony analyses revealed a robustly supported monophyletic Miliusa clade $(\mathrm{PP}=1.00 ; \mathrm{BS}=93 \%)$. Miliusa vidalii nested within clade $\mathrm{D}(\mathrm{PP}=1.00 ; \mathrm{BS}=85 \%)$ shares similar features by having terminal inflorescences and a notably long pedicel. M. vidalii is resolved as sister to M. lanceolata, which shares morphological features such as length of pedicels, number of secondary veins, shape of leaf apex, and apiculate monocarp. This present study revealed that $M$. vidalii possesses a conspicuous glandular structure in the inner petals, a feature that is common only to species found in clade A. Therefore, increased taxon sampling is necessary to construct a stronger phylogenetic relationship within the genus.
\end{abstract}

Keywords: Bayesian inference, cpDNA markers, Miliusa, parsimony analysis, Philippine endemic

\section{Introduction}

Annonaceae (Soursop family) or custard apple family belongs to the order Magnoliales and are composed of approximately 2,400 species in 107 genera of trees, shrubs and woody vines (Guo et al. 2017). The family can easily be recognized by a combination of the following characters: leaves simple, alternate phyllotaxy with a characteristic spicy odor, fruits are edible with fleshy spines and slightly acidic fibrous pulp and flowers that are hermaphroditic with trimerous perianth more or less distinctly differentiated into sepals and petals (Silberbauer-Gottsberger et al. 2003). Annonaceae are widely distributed in tropical and subtropical regions and thrives especially in lowland rainforests such as the Philippines. The family is well known for their economic importance as a

${ }^{1}$ Department of Natural Sciences, College of Arts and Sciences, University of the East, 2219 C.M. Recto Ave, Manila, 1008 Philippines ${ }^{2}$ The Graduate School, College of Science and Research Centre for the Natural \& Applied Sciences University of Santo Tomas, España, Manila 1015, Philippines

*Corresponding email: axel.arriola@ue.edu.ph

Date Submitted: 17 March 2019

Date Accepted: 11 August 2019 source of edible fruits (Annona squamosa L., A. muricata L., and $A$. reticula L.), oils for perfumes (Cananga odorata Hook. $\mathrm{f}$. \& Thomson), insecticidal compounds (Phaeanthus ebracteolatus (C. Presl.) Merr.) and as ornamental (Polyalthia flava Merr.).

One of the most diverse groups in Annonaceae is the tribe Miliuseae with approximately 510 species (Chatrou et al. 2012) and was first described by Hooker and Thomson in 1855 in their Flora Indica based on the following characters: petals valvate, carpels free, stamens loosely imbricate and anthers are visible in flowers. The distinguishing characteristics of Miliuseae have been based primarily on the presence of a miliusoid stamen that is having a stamen without a protruding connective prolongation. The tribe is predominantly distributed in tropical and subtropical Asia, Australia and Oceania and across the continental Southeast Asia and Malesia.

Miliusa is one of the most specious genera of Miliuseae as represented by 50 species of shrubs to large trees and is distributed from the Indian subcontinent, southern China and Southeast Asia, New Guinea (including D'Entrecasteaux Islands and Louisiade Archipelago) and Northern Australia (Chaowasku \& Keßler 2006). According to Chaowasku \& Keßler (2006), Miliusa is currently circumscribed by having: 1) equally-sized sepals and outer petals, both of which are smaller than the inner petals; 2) densely hairy torus; 3) miliusoid stamens; and 4) four- 
part-lamellate rumination of the endosperm. The name Miliusa was created to accommodate species under the Hyalostemma Wall. and Saccopetalum Benn. since Baillon (1868) considered that the number of ovules was too weak to support them as separate genera resulting to the transfer of all species under the two latter genera to Miliusa (Baillon 1868; Sinclair 1955). Meanwhile, Miliusa was divided into four informal groupings based on floral diversity: the $M$. mollis group, M. horsfielldii group, M. velutina group and M. campanulata group. Molecular phylogenetic work of Chaowasku and Keßler (2013) revealed a monophyletic Miliusa with four sublcades/subgroups; however, the previously proposed informal groupings for the genus were not supported. For instance, clades $\mathrm{C}$ and $\mathrm{B}$ comprise of species classified under M. mollis group and M. campanulata group, respectively, while clades $\mathrm{A}$ and $\mathrm{D}$ do not produced any distinct pattern since species under these clades are composed of representatives either from $M$. horsfieldii or $H$. velutina groups. However, Chaowasku and Keßler (2013) proposed that a correlation between clades and habitat preferences can be observed; thus, the four subclades were classified as clades A and $\mathrm{D}$ that prefer deciduous/dipterocarpus forest of dry habitat while species in clades B and $\mathrm{C}$ prefer humid, dry/moist evergreen habitat.

In the Philippines, the genus Miliusa is only represented by Miliusa vidalii J. Sinclair, (Sinclair 1955) (Fig. 1) a name that was created to accommodate the transfer of Saccopetalum longipes to Miliusa based on two reasons; 1) the transfer of all Saccopetalum to Miliusa and 2) to avoid the creation of a homonym since $M$. longipes is a valid name. In the previous work of Chaowasku \& Keßler (2013), only species from Borneo, Indonesia, Malaysia, Papua New Guinea and Thailand were included since there was no available DNA material for Miliusa in other geographic locations including the Philippines. Therefore, in this study, the phylogenetic position of the Philippine endemic $M$. vidalii was determined utilizing molecular data.

\section{Materials and Methods}

\section{Taxon Sampling and Morphological Analysis}

The botanical fieldwork was conducted at Mt. Arayat, Pampanga based on previous collections since there were no sightings of Miliusa vidalii in Mt. Mariveles Bataan, which is the protologue of Miliusa vidalii stated in the recent work of Mols and Keßler (2003). Two to three branches of vegetative and reproductive structures were collected for herbarium sheet preparation that served as voucher specimen. Herbarium sheets were submitted to USTH for accessioning. Reproductive structures were preserved in $70 \%$ ethanol. Two to three pieces of leaf material was preserved in silica gel for DNA extraction following the protocol of Chase and Hills (1991). All vegetative parts were measured using a vernier caliper (Disston) and a ruler and reproductive structures were examined using a Stereomicroscope (Olympus). Measurements and colors were based on herbarium sheets and field notes.

\section{Molecular Method}

Total chloroplast DNA was extracted from the silica-gel dried leaves by following the protocol of DNeasy Plant Mini Kit (Qiagen, Germany). Amplification of trnL-F, matK, $n d h F$, and trnH-psbA (widely used in inferring phylogenetic relationships in Annonaceae) was done using the Biometra $\mathrm{T}$ personal cycler (Germany). Amplification of the $t r n L-F$ were carried out using the following settings: $94^{\circ} \mathrm{C}$ for 3 min.; 30 cycles of $93^{\circ} \mathrm{C}$ for 1 min., $55^{\circ} \mathrm{C}$ for $1 \mathrm{~min} ., 72^{\circ} \mathrm{C}$ for $2 \mathrm{~min}$.; and a final extension of $72^{\circ} \mathrm{C}$ for $5 \mathrm{~min}$. (Taberlet et al. 1991). Amplication of matK region was done using the protocols of Buerki et al. (2009) with an initial denaturation which was programed for $2 \min$ at $95^{\circ} \mathrm{C}$, followed by 35 cycles at $95^{\circ} \mathrm{C}$ for $45 \mathrm{~s}, 50^{\circ} \mathrm{C}$ for $45 \mathrm{~s}, 72^{\circ} \mathrm{C}$ for 1 min. plus a final extension $10 \mathrm{~min}$. at $72^{\circ} \mathrm{C}$. For $n d h F$, amplification was based on the protocol of Chaowasku et al. (2015). The following PCR protocol was adopted: 35 cycles of $94^{\circ} \mathrm{C}$ : $30 \mathrm{sec} ., 53^{\circ} \mathrm{C}-65^{\circ} \mathrm{C}: 1 \mathrm{~min}$. annealing, $72^{\circ} \mathrm{C}: 2 \mathrm{~min}$., with

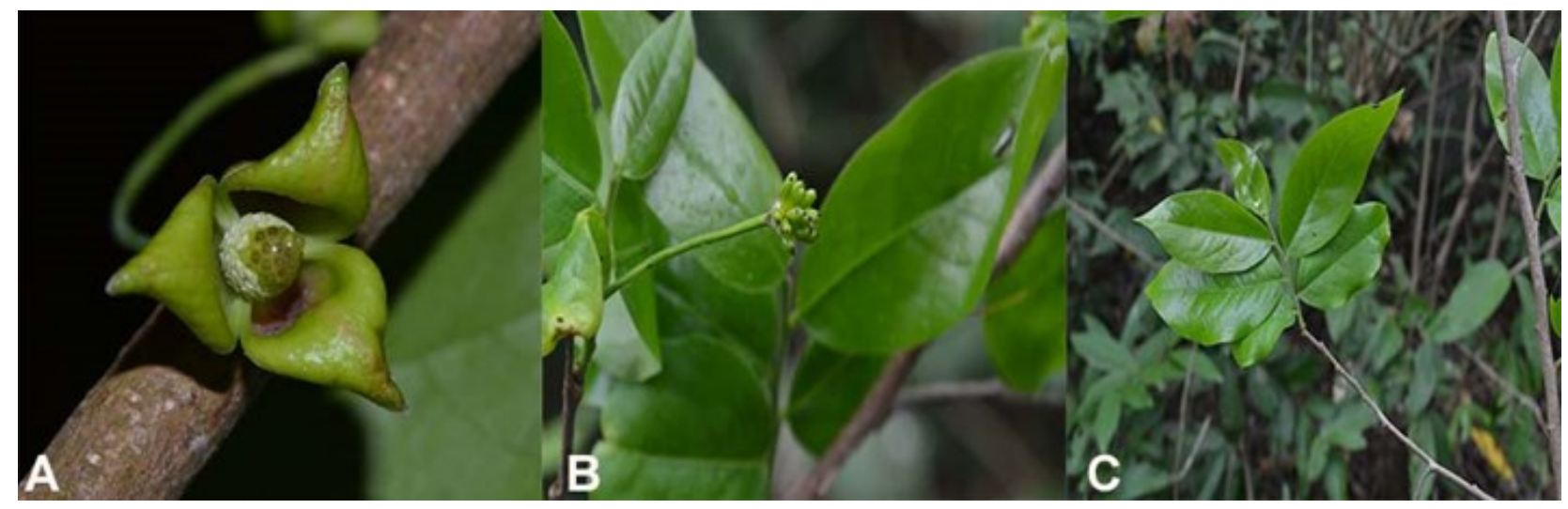

Figure 1. Miliusa vidalii (A. flower; B. young infructescences; C. sterile branch) 
the initial denaturation for $4 \mathrm{~min}$. at $94^{\circ} \mathrm{C}$ and the final extension for $7 \mathrm{~min}$. at $72^{\circ} \mathrm{C}$. The amplified DNA of $\operatorname{trn} L-F$, $m a t K, n d h F$, and trnH-psbA was purified using the QIA-quick purification Kit (Qiagen, Germany) then the presence of DNA bands was checked using 1\% Agarose gel electrophoresis. For sequencing, the purified samples were sent to MACROGEN, Inc. Seoul, South Korea.

\section{Phylogenetic Analysis}

Forward and reverse sequences from MACROGEN were edited to create a consensus sequence using CodonCode Aligner v.7.1.2. Four newly generated sequences were aligned with the related sequences from the GenBank based on the work of Chaowasku \& Keßler (2013) (GenBank Accession numbers for newly generated sequences: $\operatorname{trn} L-F=\mathrm{MN052644}$; $n d h F=\mathrm{MN} 052645 ; \quad \operatorname{mat} K=\mathrm{MN} 052645 ; \quad$ psbA$\operatorname{trn} H=\mathrm{MN052646)}$. Parsimony analysis was conducted using PAUP v. 4.0b (Swofford 2000). Most parsimonious trees were determined using heuristic search, tree-bisection reconnection (TBR) branch swapping, using 10,000 random addition sequences, with MULTREES option on. Consistency index (CI) and retention index (RI) were calculated to determine if the data is far from being homoplasious. Bootstrapping were determined using 10,000 replicates, MULTREES option off, TBR branch swapping, and five random addition sequences. Clades receiving a bootstrap (BS) value greater than 90\% were considered strongly supported (Arriola et al. 2018). Topologies from the parsimony analysis are compared with Bayesian Inference (BI) analysis using MrBayes v.3.1.2p software (Huelsenbeck and Ronquist 2001; Ronquist and Huelsenbeck 2003; Altekar et al. 2004). Bayesian model was generalized time-reversible plus gamma $(\mathrm{GTR}+\mathrm{G})$ for all partitions (temp $=0.08$; ngen $=1000000$; burnin $=500$ ). Clade with posterior probability (PP) exceeding 0.95 was regarded as strongly supported (Achille et al. 2006).

\section{Results and Discussions}

\section{Sequence Characteristics}

Matrix characteristics of the separate $t r n L-F, \operatorname{mat} K, n d h F$, trnH-psbA, ycfl and combined data sets were summarized in Table 1. The aligned trnL-F sequenced data of 42 taxa contained 993 characters, 76 of which are considered parsimony informative ( $\mathrm{RI}=0.87$ : $\mathrm{CI}=0.84)$. The aligned matK sequenced data of 20 taxa and 836 characters, 30 of which are parsimony informative $(\mathrm{RI}=0.95: \mathrm{CI}=0.94)$. For the aligned $n d h F$ sequenced data with 22 taxa and 1933 characters, 101 are considered parsimony informative $(\mathrm{RI}=0.86$ : $\mathrm{CI}=0.81)$. For the aligned trnH-psbA sequenced data with 42 taxa and 461 characters, 54 of which are considered parsimony informative $(\mathrm{RI}=0.91: \mathrm{CI}=0.87)$. For the aligned $y c f 1$ sequenced data with 22 taxa and 1511 characters, 102 that are considered parsimony informative $(\mathrm{RI}=0.85$ : $\mathrm{CI}=0.97)$. Meanwhile for the combined data sets a total of 42 taxa were used with 7199 total characters, 400 of which are considered parsimony informative. The retention index (RI) and consistency index (CI) for the combined analysis are 0.84 and 0.85 , respectively.

\section{Phylogenetic Position of Miliusa vidalii}

The BI and MP analyses of the separate $\operatorname{trn} L-F, n d h F$, $m a t K$, $p s b A$ - trnH (except for the $y c f 1$ region since we were not able to amplify it) regions showed the monophyly of the Miliusa clade (clades not shown). However, internal polytomies were observed and we were not able to recover the tree topology from the previous work of Chaowasku \& Ke $\beta$ ler (2013).

The majority-rule consensus tree from the combined sequence data (Fig.2) showed a robustly supported (BS $=100 \%$, $\mathrm{PP}=1.00$ ) monophyletic Miliusa clade similar to the phylogenetic work of Chaowasku \& Keßler (2013). The phylogenetic placement of $M$. vidalii is revealed here for the first time, which appears to form a sister-relationship with $M$. laceolata with a strong support values ( $\mathrm{BS}=93 \%$ : $\mathrm{PP}=0.94)$.

Table 1. Sequenced characteristics of the separate and combined analysis

\begin{tabular}{cccccc}
\hline Type of DNA & $\begin{array}{c}\text { No. of } \\
\text { taxa }\end{array}$ & $\begin{array}{c}\text { No. of Character } \\
\text { used }\end{array}$ & $\begin{array}{c}\text { No. of Parsimony } \\
\text { characters }\end{array}$ & $\begin{array}{c}\text { Retention } \\
\text { Index }\end{array}$ & Consistency Index \\
\hline $\boldsymbol{t} \boldsymbol{m} \boldsymbol{L}-\boldsymbol{F}$ & 42 & 993 & 76 & 0.87 & 0.84 \\
$\boldsymbol{m a t} \boldsymbol{K}$ & 20 & 836 & 30 & 0.95 & 0.94 \\
$\boldsymbol{n} \boldsymbol{d} \boldsymbol{h} \boldsymbol{F}$ & 22 & 1933 & 101 & 0.86 & 0.81 \\
$\boldsymbol{p} \boldsymbol{s} \boldsymbol{b} \boldsymbol{A}$-trn $\boldsymbol{H}$ & 42 & 461 & 54 & 0.91 & 0.87 \\
$\boldsymbol{y} \boldsymbol{c} \boldsymbol{I}$ & 22 & 1511 & 102 & 0.85 & 0.97 \\
Combined & 42 & 7199 & 400 & 0.84 & 0.85 \\
\hline
\end{tabular}




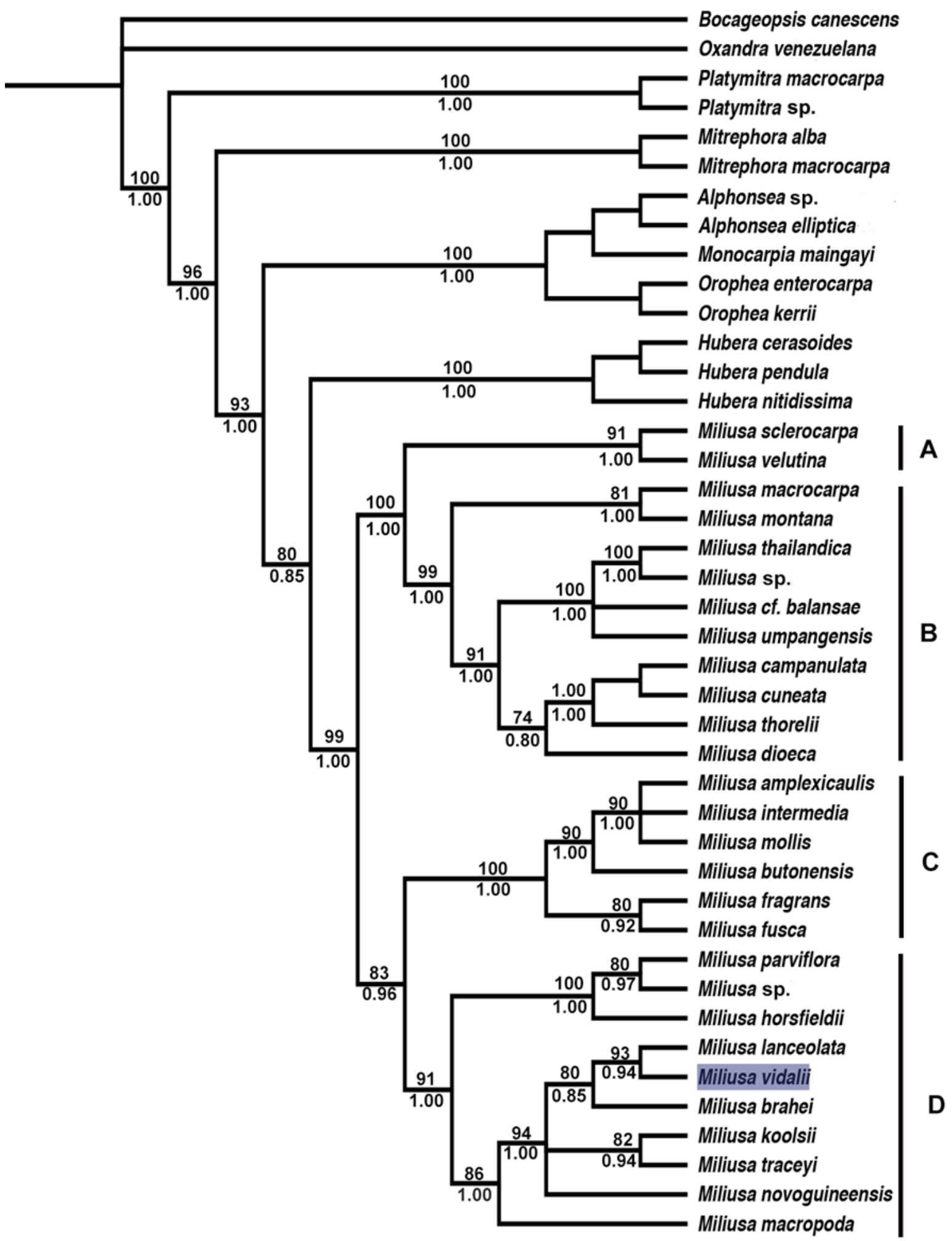

Figure 2. Majority-rule consensus tree of the combined chloroplast markers. These results are congruent with parsimony analysis. Numbers above branches indicate parsimony bootstrap values and those below are Bayesian posterior probabilities. Miliusa vidalii is highlighted in grey. 
Consultations of available taxonomic keys and recent descriptions revealed that $M$. vidalii and M. lanceolata have various morphological similarities that include the presence of long pedicels (5.5 - $9 \mathrm{~cm}$ long), acute to acuminate leaf apex, 6 - 11 secondary veins, and non apiculate monocarps.

The four strongly supported clades (clades A, B, C and D) were likewise recovered in this study with $M$. vidalii nesting in clade D. Morphological examination of our material and consultation of various available botanical descriptions (Mols and Keßler 2003, 2004) revealed that M. vidalii exhibited features similar with representatives from clade D such as terminal inflorescences and a notably long pedicel. In contrast to the report of Chaowasku \& Keßler (2013), the placement of M. vidalii within clade D revealed that not all species of the group are New Guinean in origin. In addition, a conspicuous glandular structure in the inner petals running along the bilateral midline is present in M. vidalii, a character that is common in species found in clade A. Therefore this study concur with the observation of Chaowasku \& Keßler (2013) that clades A and D are composed of species with similar and overlapping features.

\section{Conclusion}

Molecular data revealed the phylogenetic placement of the Philippine endemic M. vidalii within the monophyletic Miliusa clade specifically nesting within clade D. Morphological features revealed its relationship with the group by having similar inflorescences and length of the peduncle. However, $M$. vidalii possesses features that are similar to clade A such as the presence of conspicuous glandular structure in the inner petal and Asian in origin. Hence, current delineation of the tribe Miliuseae sensu Chaowasku \& Keßler should be revisited by including more samples of Miliusa. Meanwhile, molecular data supported by morphology revealed that $M$. vidalii appears to be sister to M. lanceolata.

\section{Literature Cited}

Achille F., T. Motley, P. Lowry, \& J. Jérémie, 2006. Polyphyly in Guettarda L. (Rubiaceae, Guettardeae) based on nrDNA ITS sequence data. Annals of the Missouri Botanical Garden, 93(1): 103-121

Altekar G., S. Dwarkadas, J. Huelsenbeck \& F. Ronquist, 2004. Parallel metropolis coupled Markov chain Monte Carlo for bayesian phylogenetic inference. Bioinformatics, 20(3): 407 $-415$.

Arriola A.H., A.P. Davis, N.M.J. Davies, U. Meve, S. LiedeSchumann, \& G.J.D. Alejandro, 2018. Using multiple plastid DNA regions to construct the first phylogenetic tree for the Asian genera of Coffeeae (Ixoroideae, Rubiaceae). Botanical Journal of Linnean Society, 188: 132-143.

Baillon H., 1868. Histoire des plantes I: 193-288. Hachette et Cie, Paris.

Buerki S., F. Forest, P. Acevedo-Rodríguez, M.W. Callmander, J.A.A. Nylander, M. Harrington, I. Sanmartín, P. Küpfer, \& N. Alvarez, 2009. Plastid and nuclear DNA markers reveal intricate relationships at subfamilial and tribal levels in the soapberry family (Sapindaceae). Molecular Phylogenetics and Evolution, 51: 238-258.

Chaowasku T., \& P.J.A. Kessler, 2006. Miliusa lanceolata (Annonaceae), A New species from Papua New Guinea. Blumea, 51: 553-557.

Chaowasku T. \& P.J.A. Kessler, 2013. Phylogeny of Miliusa (Magnoliales: Annonaceae: Malmeoideae: Miliuseae), with descriptions of two new species from Malesia. European Journal of Taxonomy, 54: 1-21.

Chaowasku T., D.M. Johnson, V.D. Ham, \& L.W. Chatrou, 2015. Huberantha, a replacement name for Hubera (Annonaceae: Malmeoideae: Miliuseae). Kew Bulletin,70: 23.

Chase M.W. \& H.H. Hills, 1991. Silica Gel: An ideal material for field preservation of leaf samples for DNA studies. Taxon 40(2): 215.

Chatrou L. W., M.D. Pirie, R.H.J. Erkens, T.L.P. Couvreur, K.M. Neubig, J.R. Abbott \& J. Mols, 2012. A new subfamilial and tribal classification of the pantropical flowering plant family Annonaceae informed by molecular phylogenetics. Botanical Journal of the Linnean Society, 169: 5-40.

Elmer A.D.E., 1939. Miscellaneous new species. Leaflets of Phillippine Botany, 10: 3684-3692.

Guo X., C. Tang, D.C. Thomas, T.L.P Couvreur, \& R.M.K. Saunders, 2017. A mega-phylogeny of the Annonaceae: taxonomic placement of five enigmatic genera and support for a new tribe, Phoenicantheae. Scientific Reports, 7: 7323.

Hooker J.D., \& T. Thomas, 1855. Flora indica: being a systematic account of the plants of British India, together with observations on the structure and affinities of their natural orders and genera. W. Pamplin, London, UK.

Huelsenbeck J.P., \& F. Ronquist, 2001. MRBAYES: Bayesian inference of phylogenetic trees. Bioinformatics, 8:754-755.

Mols J.B., \& P.J.A. Kessler, 2003. The Genus Miliusa (Annonaceae) in the Austro-Malesian area. Blumea, 48: 421 -462 .

Mols J.B., \& P.J.A. Kessler, 2004. The Genus Miliusa in the Austro-Malesian area (Annonaceae), a rectification. Blumea, 49: 350.

Ronquist, F., \& J.P. Huelsenbeck, 2003. MrBayes 3: Bayesian 
phylogenetic inference under mixed models.

Bioinformatics, 19(12):1572-4.

Silberbauer-Gottsberger I., G. Gottsberg \& A.C. Webber, 2003.

Morphological and functional flower characteristics of new and old world Annonaceae with respect to their mode of pollination. Taxon, 52(4): 701-718.

Sinclair J., 1955. A revision of the Malayan Annonaceae. Gardens' Bulletin, 14: 149-516.

Swofford, D.L., 2003. PAUP: Phylogenetic Analysis Using Parsimony version 4.0b. Sinauer Associates, Sunderland, MA.

Taberlet, P., L. Gielly, G. Pautou \& J. Bouvet, 1991. Universal primers for amplification of three non-coding regions of chloroplast DNA. Plant Molecular Biology, 17: 1105-1109. 